\title{
A Simple and Reliable Method for Intracorporeal Circular-Stapled Esophagojejunostomy Using a Hand-Sewn Over-and-Over Suture Technique in Laparoscopic Total Gastrectomy
}

\author{
Takeru Matsuda, $\mathrm{MD}^{1}$, Takeshi Iwasaki, $\mathrm{MD}^{1}$, Masaaki Mitsutsuji, $\mathrm{MD}^{1}$, Kenro Hirata, $\mathrm{MD}^{1}$, Daisuke Tsugawa, \\ $M^{1}$, Yutaka Sugita, $\mathbf{M D}^{1}$, Etsuji Shimada, $\mathrm{MD}^{1}$, and Yoshihiro Kakeji, $\mathrm{MD}^{2}$ \\ ${ }^{1}$ Department of Surgery, National Hospital Organization Kobe Medical Center, Kobe, Japan; ${ }^{2}$ Division of Gastrointestinal \\ Surgery, Department of Surgery, Kobe University Graduate School of Medicine, Kobe, Japan
}

\begin{abstract}
Background. The controversy regarding laparoscopic total gastrectomy (LTG) is mainly due to the difficulty associated with esophagojejunostomy during this procedure. Although several techniques have so far been reported to overcome this issue, ${ }^{1-4}$ a reliable technique has not yet been established. We developed intracorporeal esophagojejunostomy using a circular stapler in LTG with a hand-sewn over-and-over suture technique, and have shown its favorable outcomes compared with those of conventional open surgery. ${ }^{5}$ This technique is presented in the video.

Methods. After transection of the esophagus, an over-andover suture with a 2-0 monofilament is placed counterclockwise from the right to the left side of the cut end in an outside-to-inside direction, and then from the left to the right side in an inside-to-outside direction. After insertion of the anvil head into the esophagus, it was fixed by ligation of the thread. Finally, intracorporeal esophagojejunal anastomosis was performed using a circular stapler.

Results. In LTG, reconstruction using this method was performed for 23 consecutive patients with gastric cancer. There were no serious intraoperative complications or need for conversion to open surgery. Anastomotic leakage and stenosis occurred in one case each, respectively. The mean
\end{abstract}

Electronic supplementary material The online version of this article (doi:10.1245/s10434-015-4541-0) contains supplementary material, which is available to authorized users.

(C) Society of Surgical Oncology 2015

First Received: 20 February 2015;

Published Online: 7 May 2015

T. Matsuda, MD

e-mail: takerumatsuda@nifty.com time for fixation of the anvil to the esophagus was $15 \mathrm{~min}$ for the last 12 consecutive patients.

Conclusions. This method is simple and feasible, and the advantage of this technique is the elimination of the backhand stroke throughout the suturing procedure.

\section{REFERENCES}

1. Inaba K, Satoh S, Ishida Y, Taniguchi K, Isogaki J, Kanaya S, et al. Overlap method: novel intracorporeal esophagojejunostomy after laparoscopic total gastrectomy. J Am Coll Surg. 2010;211: e25-9.

2. Kinoshita T, Oshiro T, Ito K, Shibasaki H, Okazumi S, Katoh R. Intracorporeal circular-stapled esophagojejunostomy using handsewn purse-string suture after laparoscopic total gastrectomy. Surg Endosc. 2010;24:2908-12.

3. Omori T, Oyama T, Mizutani S, et al. A simple and safe technique for esophagojejunostomy using the hemidouble stapling technique in laparoscopy-assisted total gastrectomy. Am J Surg. 2009;197: e13-7.

4. Takiguchi S, Sekimoto M, Fujiwara $\mathrm{Y}$, et al. A simple technique for performing laparoscopic purse-string suturing during circular stapling anastomosis. Surg Today. 2005;35:896-9.

5. Matsuda T, Iwasaki T, Mitsutsuji M, et al. Surgical outcomes of intracorporeal circular-stapled esophagojejunostomy using modified over-and-over suture technique in laparoscopic total gastrectomy. Surg Endosc. 2015. 